\title{
Congenital neuromuscular disease with type I fibre hypotrophy, ophthalmoplegia and myofibril degeneration
}

\author{
H SUGIE, R HANSON, G RASMUSSEN, M ANTHONY VERITY \\ From the Department of Pathology (Neuropathology), Jerry Lewis Neuromuscular Institute and Brain \\ Research Institute, UCLA Center for the Health Sciences and Department of Neurology, Southern \\ California Permanente Medical Group, Los Angeles, California, USA
}

SUMMARY We report a 7-year-old boy with progressive, early onset somatic and cranial muscle weakness associated with external ophthalmoplegia, facial weakness, type I fibre hypotrophy and myofibril degeneration. We separate this condition from congenital fibre type disproportion because of the facial weakness, ophthalmoplegia, central nucleation, and lysis in type I fibres. The case, which is similar to that described by Bender and Bender (1977), nosologically should be classified between the centronuclear myopathies and congenital fibre type disproportion, and most likely represents a congenital or neonatal disturbance of trophic interaction between nerve and muscle.

Selective smallness of Type I fibres has been noticed in various stationary or slowly progressive congenital neuromuscular disorders. Although cranial and somatic muscles are commonly involved, eye muscle weakness, or ophthalmoplegia is unusual except in myotubular myopathy ${ }^{1-11}$ and congenital myasthenia gravis. Bender and Bender ${ }^{12}$ described an infant with severe congenital somatic and cranial muscle weakness associated with complete external ophthalmoplegia, type I fibre hypotrophy and intact neuromuscular junctions. In this report we present a second case of this rare type of congenital neuromuscular disease and compare its clinical characteristics with the other similar conditions. We distinguish this congenital neuromyopathy from myotubular (centronuclear) neuromyopathy and congenital fibre type disproportion on clinical and histological grounds. Our 7year-old male patient presented with generalised weakness associated with blepharoptosis, ophthalmoplegia, type I fibre hypotrophy and focal zones of myofibrillar lysis.

\section{Case report}

The patient, a $7 \frac{1}{2}$-year-old boy, was delivered by Caesarian Address for reprint requests: $M$ Anthony Verity, MD, Department of Pathology, UCLA School of Medicine, Los Angeles, California, 90024, USA.

Received 23 November 1981

Accepted 30 January 1982 section due to foetal distress. During the pregnancy, foetal movement was normal. He had asphyxia at birth and required intensive care for one month because of poor sucking and hyptonia. Body weight gain was slow and weak sucking remained throughout infancy. During infancy, a neuromuscular problem was suspected. He walked without support at 14 months but was clumsy and fell frequently. Recurrent infection, including upper respiratory and gastrointestinal infections, required hospitalisation for pneumonia and gastroenteritis. After entering school he revealed an inability to keep up with his peers, frequently falling with difficulty arising and in climbing stairs. Blepharoptosis became apparent in the past year and this problem worsened with fatigue. There was no positive family history of any type of neuromuscular disorder, but two male siblings died in infancy of unknown causes.

The patient was thin with small muscle bulk. He had mild bilateral blepharoptosis, complete ophthalmoplegia and mild lordosis. He showed a waddling gait, was able to climb stairs only with great difficulty and evidenced symmetrical proximal weakness, especially in the legs. Deep tendon reflexes were absent but there were no bulbar signs. Tensilon test was negative. The following laboratory studies were normal; blood count, creatine kinase, transaminase, serum electrolytes, lactate, pyruvate, sedimentation rate, EEG and CT scan of the head. Routine needle electromyography revealed low amplitude potentials but no myotonic discharges. Nerve conduction studies were normal for age.

\section{Materials and methods}

A left deltoid muscle biopsy was prepared for routine histochemistry and electron microscopy. ${ }^{13} 14$ Electron micros- 
copy was performed on $10 \times 2 \mathrm{~mm}$ cylinders of longitudinally oriented muscle elongated on Whatman filter paper and fixed in $0.1 \mathrm{M}$ sodium cacodylate buffered $2.5 \%$ glutaraldehyde. Approximately $1 \mathrm{~mm}$ cylinders were cut with razor blades and secondarily fixed in $1 \%$ osmium tetroxide, dehydrated with graded methanol-propylene oxide and embedded in Epon 812 resin. One micron sections were stained with toluidine blue and subsequent thin sections stained with lead citrate-uranyl acetate.

\section{Results}

\section{LIG HT MICROSCOPY}

There was minor distortion of the fascicular architecture with moderate variation in fibre size. Approximately $12 \%$ of fibres had internal sarcolemmal nuclei (fig 1). No increase in connective tissue or evidence of fibre necrosis, regeneration or inflammation was seen. Morphohistometric analysis of the fibre diameters performed on routine myofibrillar ATPase stained sections (fig 2) showed type I fibre predominance (type I, 86.7\%; type II, 13.3\%) and small type I fibres (figs 3,4 ). In approximately $5 \%$ of type I fibres, myofibrillar ATPase and dehydrogenase reactions revealed non-reactive central regions consistent with myofibril degeneration. These areas were single. often eccentric, and occasionally replaced two-thirds or more of the transverse fibre diameter, but were not revealed in PAS, Gomori

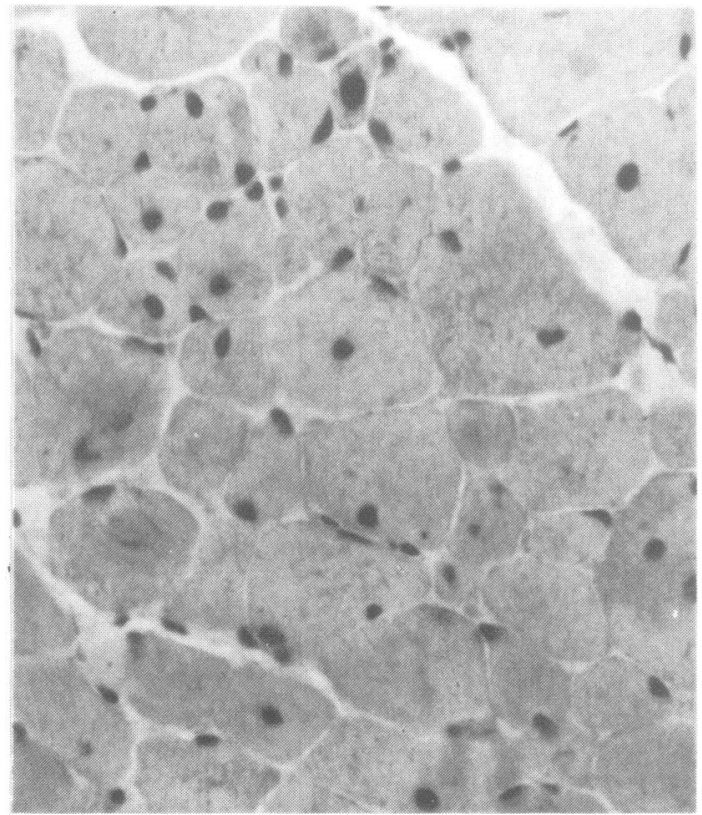

Fig 1 Cryostat section revealing fibre size variation and occasional central nucleation. Note absence of endomysial fibroplasia. $H \& E . \times 280$

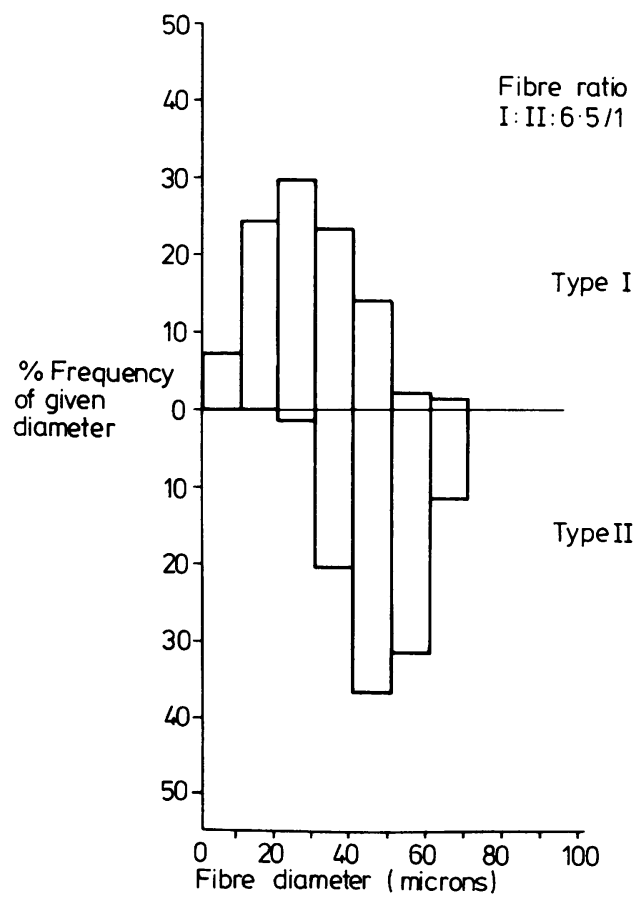

Fig 2 Frequency histogram of minimum fibre diameters. Analysis performed on sections reacted with myofibrillar ATPase, pH 9.4.

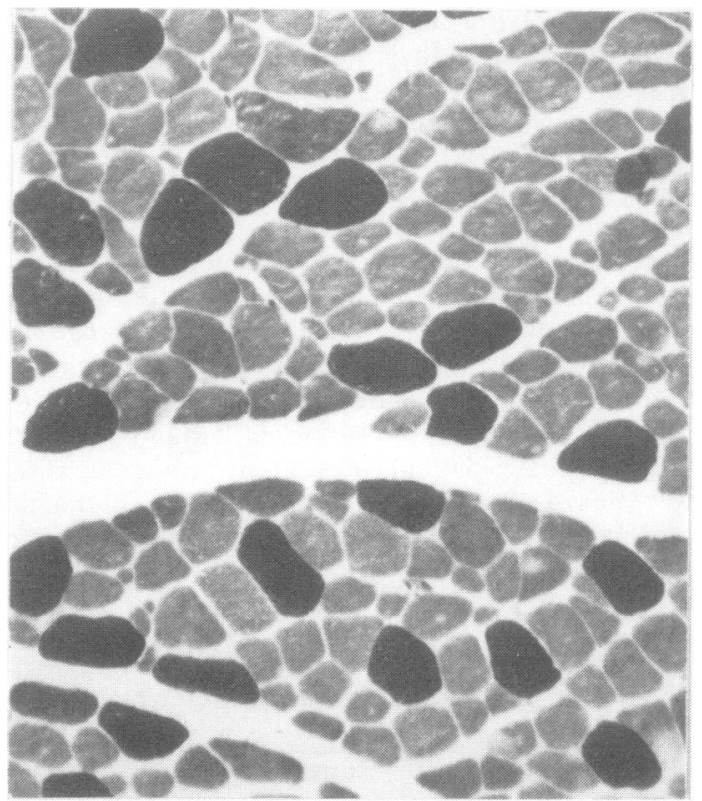

Fig 3 Note preferential type I fibre size variation and hypotrophy. Myofibrillar ATPase, preincubated pH 9.4. $\times 120$ 
trichrome, $\mathrm{H}$ and $\mathrm{E}$ or phosphorylase reactions. The incidence (fig 5) of the lesion was similar in myofibrillar ATPase and dehydrogenase reactions (table 1). Minor disruption of the sarcotubular network was

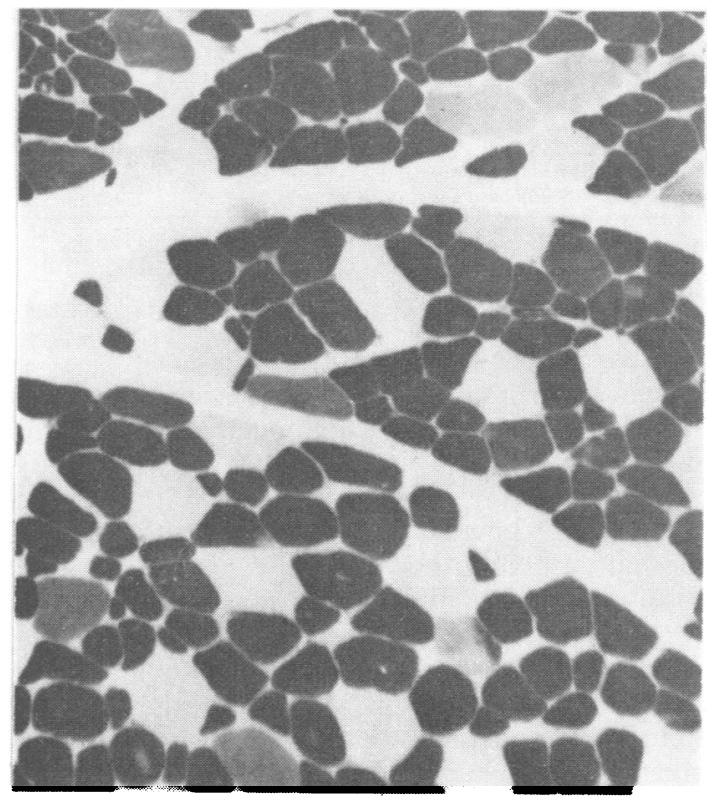

Fig 4 Reversal myofibrillar ATPase after preincubation, pH 4.3. Note type I fibre hypotrophy and presence of type IIC fibres. $\times 120$

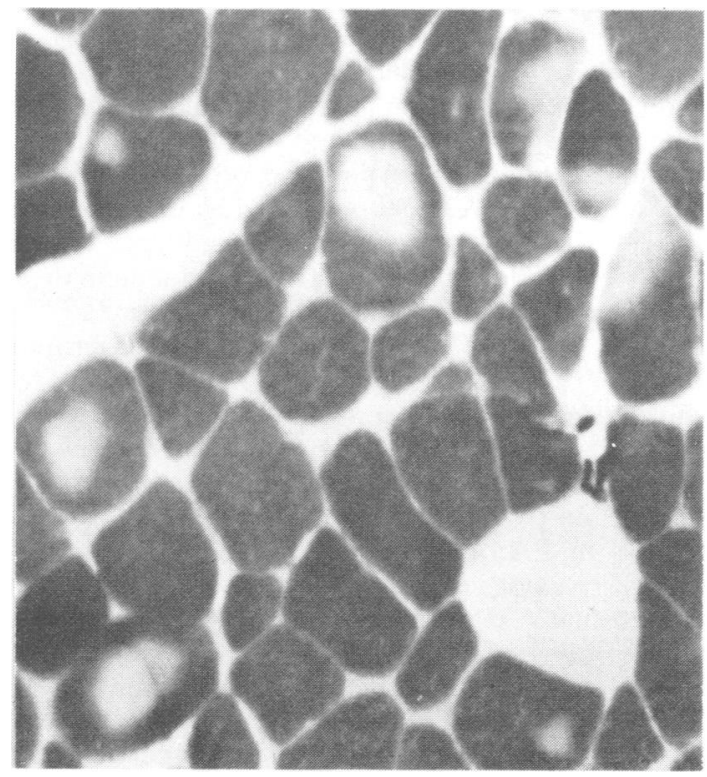

Fig 5 Central and eccentric zones of myofibrillar degeneration in type I fibres. Myofibrillar ATPase after preincubation, pH 4.3. $\times 280$
Table 1 Characteristics and incidence of myofibrillar degeneration

\begin{tabular}{llcl}
\hline & $\begin{array}{c}\text { Total } \\
\text { fibres }\end{array}$ & $\begin{array}{c}\text { Myofibrillar } \\
\text { degeneration }\end{array}$ & $\begin{array}{l}\text { Incidence } \\
(\%)\end{array}$ \\
\hline PAS & 118 & 0 & 0 \\
Myofibrillar ATPase & 682 & 28 & $4 \cdot 1$ \\
NAD H tetrazolium & 627 & 32 & $5 \cdot 1$ \\
reductase & & 2 & 0.6 \\
Phosphorylase & 310 & 2 & \\
\hline
\end{tabular}

noted but no other specific architectural changes, whorling or ring fibre change was identified. The typical histochemical changes associated with myotubular myopathy were absent. No abnormality of acid or alkaline phosphatase reaction was seen.

\section{ELECTRON MICROSCOPY}

Of 27 fibres examined, seven revealed areas of myofibrillar disorganisation. The transition zone between normal myofibrils and areas of disorganisation was irregular and indistinct. Often finger-like processes of myofilament lysis accompanied by irregular condensations of osmiophilic $\mathrm{Z}$ band

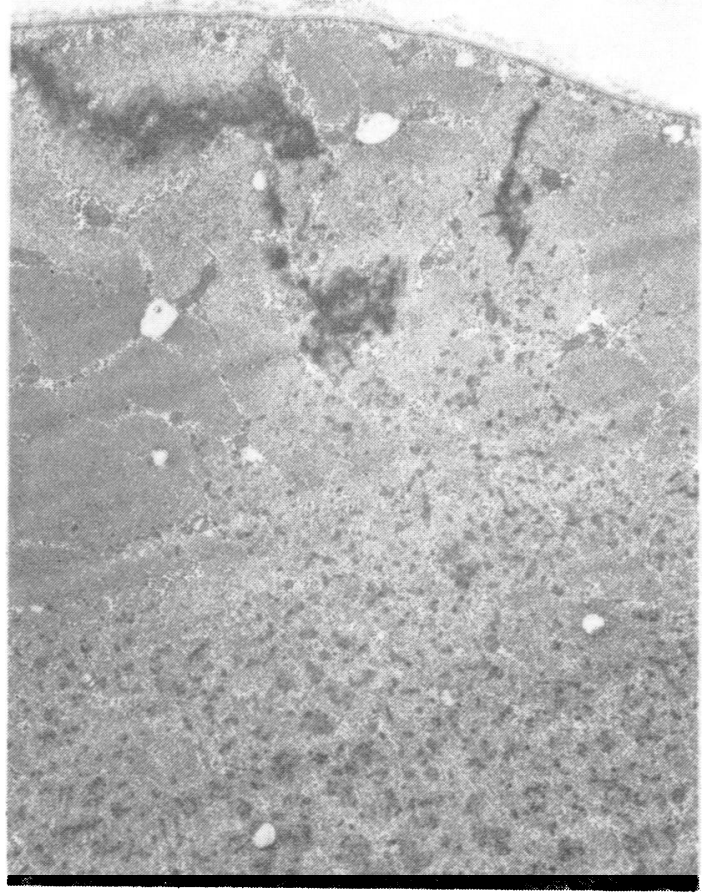

Fig 6 Transverse section of myofibre showing central myofibrillar disorganisation. The sarcolemmal membrane is intact. Irregular dense osmiophilic material arises at the sarcolemmal membrane and merges with central zones of lysis. Intact hexagonal myofilament masses are identified. Lower portion of picture reveals the region of myofibrillar lysis. $\times 5500$ 
Table 2

\begin{tabular}{|c|c|c|c|}
\hline & $\begin{array}{l}\text { Centronuclear } \\
\text { myopathy }\end{array}$ & $\begin{array}{l}\text { This case } \\
\text { Bender and Bender } 12\end{array}$ & $\begin{array}{l}\text { Congenital fibre type } \\
\text { disproportion }\end{array}$ \\
\hline $\begin{array}{l}\text { Delayed motor development } \\
\text { Ophthalmoplegia } \\
\text { Facial weakness }\end{array}$ & $\begin{array}{r}50 \% \\
>50 \% \\
70 \%\end{array}$ & $\begin{array}{l}\text { yes } \\
\text { yes } \\
\text { yes }\end{array}$ & $\begin{array}{c}>90 \% \\
0 \\
<5 \%\end{array}$ \\
\hline $\begin{array}{l}\text { Skeletal dysfunction } \\
\text { kyphoscoliosis } \\
\text { hip dislocation } \\
\text { DTR-absent } \\
\text { Myopathic EMG } \\
\text { \% of fibres with central nuclei }\end{array}$ & $\begin{aligned}>50 \% \\
<10 \% \\
>85 \% \\
50 \% \\
\geqq 50 \%\end{aligned}$ & $\begin{array}{l}\text { yes } \\
\text { no } \\
\text { yes } \\
\text { no/yes } \\
12 \% / \text { occasional }\end{array}$ & $\begin{array}{l}<20 \% \\
\sim 50 \% \\
<25 \% \\
>25 \% \\
>5 \%\end{array}$ \\
\hline
\end{tabular}

*Except for a single case which has $35 \%$ fibres with central nuclei. ${ }^{2}$

material extended to the sarcolemmal membrane (fig 6). The central areas of myofibril disorganisation contained small tenuous osmiophilic zones of presumed disrupted $\mathrm{Z}$ band in which the terminal actin filaments had lost their complex interdigitations. In these zones, there was considerable preservation of the paracrystalloid architecture of thick and thin filaments (fig 7). Only rare mitochondria were noted but glycogen granules were easily identified. Sarcoplasmic reticulum triads were spared and commonly found in the disorganised myofibril zones.

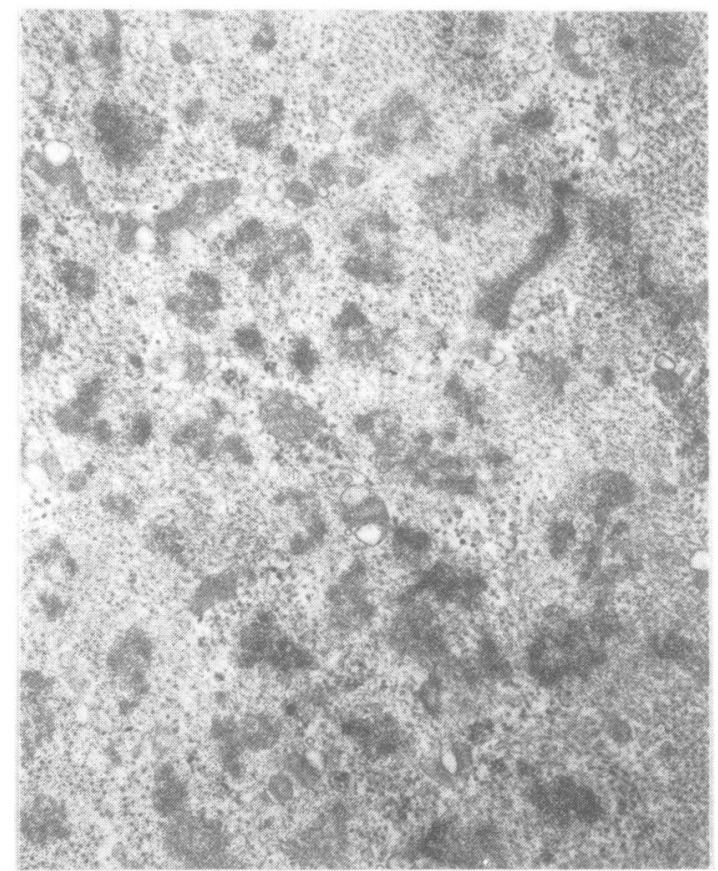

Fig 7 Detail of myofibrillar lysis with disrupted but identified masses of thick and thin filaments, preserved, slightly dilated sarcotubular triads with mitochondria, granular glycogen and moderately electron dense ill-defined masses of presumed $Z$ band material. $\times 23000$

\section{Discussion}

Selective smallness of type I muscle fibres has been described in several neuromuscular disorders, and includes myotonic dystrophy, nemaline myopathy, centronuclear myopathy, congenital fibre-type disproportion, rheumatoid arthritis, cerebellar degenerations, and other unusual congenital or early onset neuromuscular disorders. Our patient showed no fasciculations, bulbar signs, evidence of myotonia, cerebellar signs, and no joint pain or swelling. There was no elevation of serum CK, EMG alterations, and no inclusions within muscle fibres detected by electron or light microscopy. The unusual combination of early onset somatic muscle weakness and ophthalmoplegia suggests a differential diagnosis that includes centronuclear myopathy, congenital fibretype disproportion and the Benders' report ${ }^{12}$ of congenital myopathy with type I muscle fibre hypotrophy and intact neuromuscular junctions.

Our case is most similar to that of Bender and Bender. ${ }^{12}$ Brooke ${ }^{15}$ delineated the entity of congenital fibre type disproportion and reported 14 cases whose biopsies were characterised by disproportion in size of fibres with small type I and large type II fibres. No eye muscle involvement was seen in these cases. In 26 cases of centronuclear myopathy ${ }^{1-11}$ 18-2 and 23 cases of congenital fibre type disproportion $^{1528} 24$ analysed from the literature, we compared the clinical features of centronuclear myopathy with congenital fibre type disproportion (table 2 ). The histochemical findings in myotubular myopathy are distinctive. In particular, there is central accentuation or loss in PAS, myophosphorylase and dehydrogenase reaction, consistent perinuclear absence of myofibrillar ATPase and an abnormal radial orientation of the sarcoplasmic reticulum in PAS and $\mathrm{NADH}$ tetrazolium reductase. These findings were not present in the central nucleated fibre of this case. While we have made no attempt to separate cases of myotubular myopathy with or without type I fibre smallness, we are convinced that some overlap will exist. In particular, the case studies of Inokuchi, ${ }^{25}$ 
Karpati, ${ }^{19}$ Brooke, ${ }^{15}$ Williamson, ${ }^{26}$ and Engel ${ }^{27}$ report variants of centronuclear myopathy, while the studies of Prince $e t a^{28}$ and Seay et $a l^{29}$ may be classified intermediate variants of congenital fibre type disproportion. Our case and that of Bender and Bender ${ }^{12}$ falls into this overlap or intermediate group with the unique feature of ophthalmoplegia and may represent a maturation defect occurring later than at the time of myotube formation. Although morphological alterations in muscle fibres are rare in centronuclear myopathy ${ }^{30}$ and congenital fibre type disproportion, ${ }^{13}{ }^{23}$ they have some similarities to the changes in core/multi-core disease, ${ }^{31}{ }^{32}$ target formations following denervation, tenotomy, ${ }^{33}$ malignant hyperpyrexia ${ }^{34}$ and fructose 1,6-diphosphatase deficiency. ${ }^{14}$ An early focal decrease of mitochondria, myofibrillar degeneration with disintegration of $\mathrm{Z}$ line and considerable decrease in glycogen, gives rise to the characteristic histochemical and electron microscopic findings of typical unstructured cores..$^{35}$ The lesions in our case are more sporadic, involve approximately $5 \%$ of fibres, are only found in type I fibres in contrast to multi-core disease, are not revealed in PAS or phosphorylase reactions in contrast to central core and core-targetoid change after denervation and ultrastructurally reveal greater preservation of $A$ band material and sarcoplasmic triad organisation. The regions of myofibril degeneration are central in contrast to the peripherally situated zones found in familial myopathy with myofibril lysis of type I fibres. ${ }^{36}$ While we cannot determine whether the myofibrillar disorganisation is a primary or secondary degeneration, the change is limited to type I fibres, suggesting a strong relationship to the pathogenesis of fibre hypotrophy.

Whether the patient's condition is derived from neurogenic or myopathic disease is unclear, but the lack of fibre necrosis, regeneration, phagocytosis, or endomysial connective tissue proliferation with normal CK levels excludes a "myopathic" change in the ordinary sense. Engel $e a^{27}$ presented a necropsy case of type I fibre hypotrophy with central nuclei, with no abnormality in the central or peripheral nervous system. However, a large proportion of patients with centronuclear myopathy or congenital fibre type disproportion had absent deep tendon reflexes even though they probably had enough muscle power to elicit joint movement. The pathogenesis of type I fibre smallness might be explained by some defect of the monosynaptic reflex arc which would probably influence type I fibre maturation. ${ }^{26}$

The combination of type I fibre hypotrophy, predominance, sporadic myofibrillar degeneration, and ophthalmoplegia are the cardinal features in our patient and closely approximate the case of Bender and Bender. ${ }^{12}$ The prognosis should be guarded. The Benders' case was more severely involved and died during early infancy (personal communication).

This work was supported in part by USPHS HD 05615, HD 04612, and BRSG RR 05756.

\section{References}

${ }^{1}$ Spiro AJ, Shy GM, Gonatas NK. Myotubular myopathy: persistence of fetal muscle in an adolescent boy. Arch Neurol 1966;14:1-14.

2 Bethlem J, Meijer AEF, Schellens JPM, Broom JJ. Centronuclear myopathy. Europ Neurol 1968;1:325-33.

${ }^{3}$ Kinoshita M, Cadman TE. Myotubular myopathy. Arch Neurol 1968;18:265-71.

4 Badurska B, Fidzianska A, Kamieniecka Z, Prot J, Strugalska H. Myotubular myopathy. J Neurol Sci 1969;8:563-71.

5 Campbell MJ, Rebeiz JJ, Walton JN. Myotubular, centronuclear or peri-centronuclear myopathy? J Neurol Sci 1969;8:425-43.

${ }^{6}$ Munsat TL, Thompson LR, Coleman RF. Centronuclear "myotubular" myopathy. Arch Neurol 1969;20: $120-31$.

${ }^{7}$ Van Wijngaarden GK, Fleury P, Bethlem J, Meijer AEF. Familial "myotubular" myopathy. Neurol (Minneap) 1969;19:901-8.

${ }^{8}$ Bradley WG, Price DL, Watanabe CK. Familial centronuclear myopathy. J Neurol Neurosurg Psychiatry 1970;33:687-93.

- Ortiz de Zarate JC, Maruffo A. The descending ocular myopathy of early childhood: myotubular or centronuclear myopathy. Europ Neurol 1970;3:1-12.

${ }^{10}$ Palmucci L, Bertolott A, Monga G, Ardizzone G, Schiffer D. Histochemical and ultrastructural findings in a case of centronuclear myopathy. Europ Neurol 1978;17:327-32.

1 Serratrice G, Pellissier JF, Faugere MC, Gastaut JL. Centronuclear myopathy: possible central nervous system origin. Muscle Nerve 1978;1:62-9.

12 Bender A, Bender M. Muscle fiber hypotrophy with intact neuromuscular junctions. Neurol (Minneap) 1977;27: 206-12.

18 Dubowitz V, Brooke MH. Muscle Biopsy: A Modern Approach. London: WB Saunders Co, 1973.

${ }^{14} \mathrm{Kar}$ NC, Pearson CM, Verity MA. Muscle fructose 1,6diphosphatase deficiency associated with an atypical central core disease. J Neurol Sci 1980;48:243-56.

${ }^{15}$ Brooke MH. A neuromuscular disease characterized by fiber type disproportion. In: Kakulas BA, ed. Proceedings of The 2nd International Congress on Muscle Diseases, Perth, Australia, Amsterdam: Excerpta Medica, 1971:147-59 (ICS No. 282).

${ }^{16}$ Bethlem J, Van Wijngaarden GK, Meijer AEF et al. Neuromuscular disease with type I fiber atrophy, central nuclei, and myotube-like structures. Neurol (Minneap) 1969;19:705-10.

${ }^{17}$ Coleman RF, Thompson LR, Nieluis AW et al. Histochemical investigation of "myotubular" myopathy. Arch Path 1968;86:365-76.

${ }^{18}$ Bethlem J, Van Wijngaarden GK, Mumenthaler M, Mei- 
jer AEF. Centronuclear myopathy with type I fiber atrophy and "myotubes". Arch Neurol 1970;23:70-3.

${ }^{19}$ Karpati G, Carpenter S, Nelson RF. Type I muscle fiber atrophy and central nuclei: a rare familial neuromuscular disease. J Neurol Sci 1970;10:489-500.

${ }^{20}$ Harriman DG, Haleem MA. Centronuclear myopathy in old age. $J$ Path 1972;108:237-47.

${ }^{21}$ McLeod JG, Baker W de C, Lethlean AK, Shorey CD. Centronuclear myopathy with autosomal dominant inheritance. J Neurol Sci 1972;15:375-87.

${ }^{22}$ Hawkes $\mathrm{CH}$, Absolon MJ. Myotubular myopathy associated with cataract and electrical myotonia. J Neurol Neurosurg Psychiatry 1975;38:761-4.

${ }^{23}$ Lenard HG, Goebel HH. Congenital fiber type disproportion. Neuropädiatrie 1975;6:220-31.

24 Cavanagh NPC, Lake BD, McMeniman P. Congenital fiber type disproportion myopathy: a histological diagnosis with an uncertain clinical outlook. Arch Dis Child 1979;54:735-43.

${ }^{25}$ Inokuchi T, Umezaki H, Santa T. A case of type I muscle fiber hypotrophy and internal nuclei. $J$ Neurol Neurosurg Psychiatry 1975;38:475-82.

${ }^{26}$ Brooke $\mathrm{MH}$, Williamson T. An adult case of type I muscle fiber hypotrophy: an abnormality of monosynaptic reflex function. Neurol (Minneap) 1969;19:280.

${ }^{27}$ Engel WK, Gold GN, Karpati G. Type I fiber hypotrophy and central nuclei. Arch Neurol 1968;18:435-44.

${ }^{28}$ Prince AD, Engel WK, Warmolts JR. Type I myofiber smallness without central nuclei or myotonia. Neurol (Minneap) 1972;22:401.

29 Seay AR, Ziter FA, Petajan JH. Rigid spine syndrome: a type I fiber myopathy. Arch Neurol 1977;34:119-21.

so Radu H, Ionasescu V. Nemaline (neuro-myopathy): rodlike bodies and type I fiber atrophy in a case of congenital hypotonia with denervation. J Neurol Sci 1972;17:53-60.

31 Shy GM, Magee KR. A new congenital non-progressive myopathy. Brain 1956;79:610-21.

32 Engel AG, Gomez MR, Groover RV. Multicore disease: a recently recognized congenital myopathy associated with multifocal degeneration of muscle fibers. Mayo Clinic Proc 1971;46:666-81.

33 Shafiq SA, Gorycki MA, Asiedu SA, Milhorat AT. Tenotomy-effect on the fine structure of the soleus of the rat. Arch Neurol 1969;20:625-33.

34 Denborough MA, Bennett X, Anderson R. Central core disease and malignant hyperpyrexia. $\mathrm{Br}$ Med $J$ 1973;1:272-3.

${ }^{35}$ Neville HE, Brooke MH. Central core fibers-structured and unstructured. In: Kakulas BA, ed. Basic Research In Myology. Amsterdam: Excerpta Medica, 1973:497-511 (ICS No. 294).

${ }^{36}$ Cancilla PA, Kalyanaraman K, Verity MA et al. Familial myopathy with probable lysis of myofibrils in type I fibers. Neurol (Minneap) 1971;21:579-85. 